\title{
Exogenous Carbohydrate as an Ergogenic Aid: Recent Advances in Dose and Form and Format ${ }^{+}$
}

\author{
David S. Rowlands \\ School of Sport, Exercise, and Nutrition, College of Health, Massey University, 63 Wallace St, Private Box 756, \\ Wellington 6011, New Zealand; D.S.Rowlands@massey.ac.nz \\ + Presented at the 2018 Nutrition Society of New Zealand Annual Conference, Auckland, New Zealand, \\ 28-30 November 2018.
}

Published: 5 March 2019

Performance nutrition is as wide and complex topic as the number and diversity of sports available for human endeavor. Nevertheless, over 100 years of evidenced-based outcomes founded upon the science of energy-substrate metabolism provide a body of evidence providing almost certain support for the use of carbohydrate prior to and during most prolonged maximal efforts to enhance performance. This presentation will provide a summary of some of our recent research contributing to the refinements and translation of this general ergogenic theme. Topics covered will include: maximal exogenous-carbohydrate dose response; optimal fructose:glucose/maltodextrin ratio for gut comfort, oxidation rate, and performance; new data on the role of sucrose and very longchain glucose polymers in glycogen recovery; effects of solid, gel, and drink format; training of the gut, new technologies in sports drinks- the Sub2/Maurten story, and inferences from lab vs incompetition field clinical trials.

Supplementary Material: The presentation is available online at www.mdpi.com/2504-3900/8/1/10/s1.

(C) 2019 by the authors. Licensee MDPI, Basel, Switzerland. This article is an open access article distributed under the terms and conditions of the Creative Commons Attribution (CC BY) license (http://creativecommons.org/licenses/by/4.0/). 